\title{
Treatment of neuroblastoma and rhabdomyosarcoma using RGD-modified liposomal formulations of patupilone (EPO906)
}

This article was published in the following Dove Press journal:

International Journal of Nanomedicine

19 June 2013

Number of times this article has been viewed

Karine Scherzinger-Laude

Carina Schönherr ${ }^{2,3}$

Felicitas Lewrick ${ }^{3}$

Regine Süss ${ }^{3}$

Giancarlo Francese ${ }^{2, *}$

Jochen Rössler ${ }^{1, *}$

'Clinic IV, Pediatric Hematology and Oncology, Center of Pediatrics and Adolescent Medicine, University Medical Hospital Freiburg, Germany; ${ }^{2}$ Department of Technical Research and Development, Novartis Pharma AG, Basel, Switzerland; ${ }^{3}$ Department of Pharmaceutical Technology, AlbertLudwigs University, Freiburg, Germany

*Both authors contributed equally to this work as senior scientists
Correspondence: Jochen Rössler Clinic IV, Pediatric Hematology and Oncology, Center of Pediatrics and Adolescent Medicine, University Medical Hospital of Freiburg, Mathildenstrasse I, 79106 Freiburg, Germany

Tel +4976127043000

Fax +49 76I 27046160

Email jochen.roessler@uniklinik-freiburg.de
Background: Patupilone (EPO906) is a microtubule stabilizer with a potent antitumor effect. Integrin $\alpha$ V $\beta 3$-binding (RGD) liposomes were loaded with EPO906, and their antitumor efficacy was evaluated in two pediatric tumor models, ie, neuroblastoma and rhabdomyosarcoma.

Methods: Integrin $\alpha \mathrm{V} \beta 3$ gene expression, RGD-liposome cellular association, and the effect of EPO906 and liposomal formulations of EPO906 on cell viability were assessed in vitro in human umbilical vein endothelial cells (HUVEC), in the RH-30 rhabdomyosarcoma cell line, and in the Kelly neuroblastoma cell line. In vivo, mice bearing neuroblastoma or rhabdomyosarcoma tumors were treated with EPO906, EPO906-liposomes, or EPO906-RGD-liposomes. Tumor growth, cumulative survival, and toxicity were monitored.

Results: Integrin $\alpha \mathrm{V} \beta 3$ was highly expressed in HUVEC and RH-30, but not in Kelly cells. Accordingly, RGD-liposomes were highly associated with HUVEC and RH-30 cells in vitro, but not with the Kelly cells. EPO906 and its liposomal formulations inhibited HUVEC, RH-30, and Kelly cell viability to the same extent. In vivo, EPO906 $1.5 \mathrm{mg} / \mathrm{kg}$ and liposomal EPO906 potently inhibited tumor growth in both xenograft models without triggering major toxicity. At this dose, liposomal EPO906 did not enhance the antitumor effect of EPO906 in neuroblastoma, but tended to have an increased antitumor effect in rhabdomyosarcoma. Using a lower dose of EPO906-RGD-liposomes significantly enhanced cumulative survival in rhabdomyosarcoma compared with EPO906 alone.

Conclusion: EPO906 shows a strong antitumor effect in neuroblastoma and rhabdomyosarcoma, without triggering major side effects. Its liposomal encapsulation does not alter its activity, and enhances cumulative survival when EPO906-RGD-liposomes are used at low dose in rhabdomyosarcoma.

Keywords: patupilone, liposomes, integrin targeting, pediatric cancer

\section{Introduction}

Patupilone, also known as epothilone B (EPO906), is a potent microtubule stabilizer. It belongs to the class of microtubule-binding drugs known as epothilones, initially discovered as secondary metabolite macrolides produced by the myxobacterium Sorangium cellulosum, ${ }^{1}$ and rapidly shown to be taxane-like agents causing microtubule stabilization in vitro. ${ }^{2}$ Like the taxanes, patupilone binds to $\beta$-tubulin on the interior surface of microtubules but with higher affinity, although the binding site on the microtubules is probably the same. This alters spindle formation, resulting in arrest of mitotic cells and cell death via apoptosis. ${ }^{3,4}$ In comparison with taxanes such as paclitaxel, patupilone has been shown to have more potent in vivo anticancer activity at tolerated dose levels in several human xenograft models. ${ }^{3}$ Further, patupilone 
retains activity in vitro and in vivo in taxane-resistant cancer cells overexpressing $\mathrm{P}$-glycoprotein or bearing $\beta$-tubulin mutations. ${ }^{2,5}$

In addition to being directly cytotoxic to tumor cells, patupilone has antivascular and antiangiogenic effects. The tumor vasculature, which is important for tumor progression, has characteristics different to those of quiescent endothelium. Immature angiogenic endothelial cells rely on a stable microtubule cytoskeleton to support their elongated shape ${ }^{6}$ making them sensitive to microtubule-binding agents. An antiproliferative effect and induction of apoptosis in endothelial cells has been observed in vitro using protracted low doses of patupilone. ${ }^{7}$ Patupilone has also been recently described as a potent radiosensitizer in medulloblastoma. ${ }^{8}$ Moreover, it showed potency in inhibition of the invasive angiogenic response in tumor extracts and in inducing vessel and tumor regression. ${ }^{9}$ Further, a study using in situ magnetic resonance imaging and measuring interstitial fluid pressure in different tumor models showed a vascular disruptive effect of patupilone in vivo. ${ }^{10}$ These combined antivascular and antiangiogenic properties suggest that patupilone has the potential to treat solid tumors successfully by its dual activity against tumor and endothelial cells.

Pediatric solid tumors are rare cancers and drug development is not focused on these life-threatening diseases due to a lack of demand. However, intensive collaborations and elaboration of protocols used in treatment-optimizing studies and clinical trials have helped to increase survival rates by up to $75 \%$ in young patients suffering from cancer in recent decades. ${ }^{11,12}$ Neuroblastoma and rhabdomyosarcoma are among the most frequent and aggressive tumors of childhood, and still have unsatisfactory outcomes, especially in the advanced stages. ${ }^{13,14}$ New molecules and therapeutic approaches are therefore urgently needed. Both entities show particular characteristics in their molecular biology, and angiogenesis has been identified to be a potential new target in neuroblastoma as well as in rhabdomyosarcoma. ${ }^{15,16}$

The aim of efficient tumor therapy should be to improve the specificity of drug delivery in order to have a better effect without destroying or damaging healthy cells. Among the targeting strategies, encapsulation of drugs into liposomes is a possibility for increasing the amount of drug delivered to the tumor with fewer side effects, as described, eg, with liposomal doxorubicin. ${ }^{17,18}$ Liposomes are spherical nanoparticles containing a phospholipid bilayer surrounding an aqueous core. Addition of a poly(ethylene glycol) (PEG) coating delays uptake by the mononuclear phagocyte system, resulting in a prolonged systemic circulation time. ${ }^{19}$
In addition, liposomes exhibit preferential extravasation and accumulation at the site of a solid tumor because of increased endothelial permeability and reduced lymphatic drainage in the tumor tissue (ie, the enhanced permeability and retention effect). ${ }^{20}$ Liposomes can be modified further by coupling peptides or antibodies to the outer surface to bind selectively to targeted cells to be taken up specifically by these cells. For example, small peptide ligands harboring a RGD (argininelysine-aspartate) motif that is found in the extracellular matrix can bind to integrin $\alpha \mathrm{V} \beta 3$. These integrins are transmembrane proteins expressed by a number of tumor cells as well as by endothelial cells actively proliferating in and around tumor tissue. ${ }^{21-23}$ Integrin $\alpha \mathrm{V} \beta 3$ is overexpressed in the tumor endothelium, but is absent or barely detectable in established blood vessels. ${ }^{24}$ A number of RGD-grafted liposomal delivery systems have been developed in the last few years, not only to target tumor cells but also to have an antiangiogenic effect. ${ }^{17,25}$

In the present study, we investigated patupilone (EPO906) in two pediatric tumor models, ie, neuroblastoma and rhabdomyosarcoma. Inhibition of tumor growth and survival were analyzed when EPO906 was encapsulated into long-circulating PEG-coated liposomes, as well as PEG-coated liposomes additionally coupled with cyclic RGD-peptides.

\section{Materials and methods Cell lines}

Human umbilical vein endothelial cells (HUVEC), obtained from PromoCell GmbH (Heidelberg, Germany) were grown in endothelial basal medium containing $0.1 \mathrm{ng} / \mathrm{mL}$ human epidermal growth factor, $1 \mathrm{ng} / \mathrm{mL}$ basic fibroblast growth factor, $1 \mu \mathrm{g} / \mathrm{mL}$ hydrocortisone, $90 \mu \mathrm{g} / \mathrm{mL}$ heparin, and $2 \%$ fetal calf serum (endothelial cell growth medium kit, Lonza, Walkersville, MD) under $5 \% \mathrm{CO}_{2}$ at $37^{\circ} \mathrm{C}$. Human neuroblastoma Kelly cells and RH-30 human rhabdomyosarcoma cells were obtained from DSMZ (Braunschweig, Germany). Both cell lines were cultured in RPMI 1640 medium (Gibco-BRL, Eggenstein, Germany) supplemented with $10 \%$ fetal calf serum, $50 \mathrm{U} / \mathrm{mL}$ penicillin $\mathrm{G}$, and $50 \mu \mathrm{g} / \mathrm{mL}$ of streptomycin under $5 \% \mathrm{CO}_{2}$ at $37^{\circ} \mathrm{C}$.

\section{Analysis of integrin $\alpha \mathrm{V} \beta 3$ expression}

Total RNA was isolated using Trizol reagent (Invitrogen $\mathrm{GmbH}$, Darmstadt, Germany) according to the manufacturer's instructions. cDNA synthesis was performed with $1 \mu \mathrm{g}$ of total RNA using a reverse transcription kit (QuantiTect, Qiagen, Hilden, Germany). Polymerase chain reactions were 
performed on a thermal cycler system $\left(\mathrm{C} 1000^{\mathrm{TM}}\right.$, BioRad, Hercules, CA). Primer sets for integrin $\alpha \mathrm{V}$ (INT $\alpha \mathrm{V})$, integrin $\beta 3$ (INT $\beta 3$ ), and $\beta$-actin were custom-synthesized by Thermo Fisher Scientific GmbH (Erlangen, Germany) and are described elsewhere. ${ }^{23}$ Polymerase chain reaction analyses were carried out in a reaction volume of $20 \mu \mathrm{L}$ containing $18 \mu \mathrm{L}$ of GoTaq ${ }^{\circledR}$ DNA polymerase mix (Promega, Madison, WI) and $2 \mu \mathrm{L}$ of cDNA.

\section{Preparation of EPO906-encapsulated liposomes}

Patupilone was prepared by the chemical department at Novartis (Basel, Switzerland). The following reagents were used for preparation of the liposomes: unsaturated soybean phosphatidylcholine (Lipoid S100) from Lipoid (Ludwigshafen, Germany); N-carbonyl-methoxy(polyethyleneglycol2000)-1,2-distearoyl-sn-glycero-3phosphoethanolamine sodium salt ( $\left.\mathrm{mPEG}_{2000}-\mathrm{DSPE}\right)$ from Genzyme Pharmaceuticals (Liestal, Switzerland); cholesterol from Fluka (Buchs, Switzerland); cyclo(Arg-Gly-Asp-D-Phe-Cys) (RGD-peptide) and cyclo(Arg-Ala-Asp-D-Phe-Cys) (RAD-peptide) from Peptides International Inc (Louisville, KY); 1,2-distearoyl-sn-glycero3-phosphoethanolamine- $\mathrm{N}$-[maleimide(polyethylene glycol-2000)] (ammonium salt) (Mal-PEG 2000 -DSPE) from Avanti Polar Lipids Inc (Alabaster, AL); and ethanol of high-performance liquid chromatography grade from Merck (Darmstadt, Germany). For the hydration buffer, potassium monobasic and disodium hydrogen phosphate dihydrate were obtained from Fluka. For the fluorescent placebo liposomes, rhodamine B-1,2-dihexadecanoyl-snglycero-3-phosphoethanolamine (triethylammonium salt, rhodamine-PE) was obtained from Molecular Probes (Leiden, The Netherlands).

All Mal-PEG-liposome batches were produced according to a thin film hydration method described previously. ${ }^{26,27}$ Briefly, the excipients (S100/ $\mathrm{mPEG}_{2000}$-DSPE/Mal-PEG ${ }_{2000}{ }^{-}$ DSPE/cholesterol 17.71/0.69/0.52/3.48 $\mathrm{mol} / \mathrm{mol}$ ) were dissolved in ethanol and the solvent was evaporated using a rotavapor (Rotavap R 215, Büchi, Flawil, Switzerland) for one hour, slowly decreasing the pressure to $30 \mathrm{mbar}$, and dried further for two hours to remove the solvent completely. The lipid film was then hydrated with a phosphate buffer $(\mathrm{pH}$ 7.4) to yield a liposomal dispersion containing $22.4 \mathrm{mM}$ total lipid. The liposomal dispersion was extruded first through a polycarbonate membrane with $100 \mathrm{~nm}$ pores (Millipore, Billerica, MA) three times and then through a polycarbonate membrane with $50 \mathrm{~nm}$ pores (Millipore) six times. A solution of RGD-peptide (1.6 mM) in phosphate buffer (pH 7.4) was added to the liposomal dispersion and the preparation was incubated at room temperature overnight using a thermomixer at $750 \mathrm{rpm}$ to couple the RGD-peptides with the maleimide groups on the liposomal surface. The molar ratio of RGD-peptide to anchor was optimized to 1:6 using in vitro uptake experiments (data not shown). For a negative peptide targeting control, the inactive RAD-peptide was replaced with RGD as the targeting motif. In the RADpeptide structure, glycine is replaced by alanine. Therefore, the peptide does not bind to the receptor-binding pocket. The free peptide was separated from the coupled fraction by size exclusion chromatography using a Sephadex CL-4B column (Sigma-Aldrich, St Louis, MO).

The average hydrodynamic diameter of the liposomes and the particle size distribution were analyzed by photon correlation spectroscopy using a Zetasizer 3000HS from Malvern (Worcestershire, UK). First, $5 \mu \mathrm{L}$ of the liposome dispersion were diluted with $2 \mathrm{~mL}$ of phosphate buffer (pH 7.4) and then measured at $20^{\circ} \mathrm{C}$ with a $90^{\circ}$ angle. The average hydrodynamic diameter (z-average) was calculated from 10 subruns. All liposomal preparations were smaller than $100 \mathrm{~nm}$ and showed a narrow particle size distribution (polydispersity index $<0.1$, Supplementary Figure S1). The entrapment efficiency of EPO906 was assessed using a dialysis cassette (Slide-A-Lyzer ${ }^{\circledR}, 10 \mathrm{kDa}$, Thermo Fisher Scientific, Lausanne, Switzerland) to separate the free drug from the liposomal fraction. Liposomes remained inside the dialysis membrane (cutoff $10 \mathrm{kDa}$ ) while the free drug dissolved in the excess phosphate buffer $(\mathrm{pH}$ 7.4) volume of $2000 \mathrm{~mL}$ surrounding the dialysis chamber. The liposomal fraction was taken for high-performance liquid chromatography measurements to define the amount of entrapped drug substance. ${ }^{27}$ The entrapment efficiency of EPO906 was shown to be higher than 95\% for all liposomal preparations.

EPO906 dissolved in PEG 300 was used as a nonliposomal control formulation, and is referred to henceforth as EPO906, EPO906 encapsulated in PEG-liposomes as EPO906-lip, EPO906 encapsulated in RGD-PEG-liposomes as EPO906RGD-lip, and EPO906 encapsulated in RAD-PEG-liposomes as EPO906-RAD-lip.

\section{Selectivity of integrin targeting with RGD-liposomes in vitro}

To study specifically the association between RGDliposomes and integrin on endothelial and tumor cells, we prepared empty liposomes as described above and added a 
hydrophobic fluorescence marker (rhodamine-PE; $0.5 \mathrm{~mol} \%$ of total lipid). HUVEC (120,000 per well), RH-30 (80,000 per well), and Kelly (80,000 per well) cells were seeded 24 hours before incubation with $300 \mathrm{nmol}$ total lipid comprising empty fluorescent liposomes (PEG-lip, RAD-lip, or RGD-lip) for four hours at $4^{\circ} \mathrm{C}$ or $37^{\circ} \mathrm{C}$. Flow cytometry analyses were performed with a FACSCalibur ${ }^{\mathrm{TM}}$ device (Becton Dickinson, Franklin Lakes, NJ; Software Cell Quest Pro, Heidelberg, Germany) equipped with an argon laser (488 nm). A total of 10,000 events per sample were recorded.

\section{Cell viability}

Cell viability was measured by MTS assay using the CellTiter $96^{\circledR}$ aqueous non-radioactive cell proliferation assay kit (Promega). The inhibitory effect of EPO906 and the liposomal EPO906 formulations on cell viability was assessed in HUVEC, RH-30, and Kelly cells. The cells were seeded in 96-well plates (8000 HUVEC per well and 15,000 tumor cells per well) and incubated with EPO906 or the liposomal EPO906 formulations (from $0.1 \mathrm{nM}$ to $100 \mathrm{nM}$ ) for four hours. Unbound liposomes were washed away three times, and the MTS assay was performed 48 or 72 hours later.

\section{In vivo therapeutic efficacy studies}

All experiments were conducted using protocols and conditions approved by the animal care and use committee at Freiburg's University Medical Hospital. Female SCID bg/bg mice aged 5-6 weeks obtained from Charles River (Sulzfeld, Germany) were kept in groups of five animals per cage under normal conditions with access to food and water ad libitum. Tumors were induced by subcutaneous injection of Kelly cells or RH-30 cells $\left(20 \times 10^{6}\right.$ cells in $150 \mu \mathrm{L}$ of phosphatebuffered solution in the right flank), and tumor growth and body weight were monitored three times weekly. Tumor sizes were determined according to the following formula: length $\times \mathrm{d}^{2} \times \pi / 6$; where "length" is the longest dimension and "diameter $\mathrm{d}$ " is the shortest dimension.

All treatments were started when the tumor size was 150-200 $\mathrm{mm}^{3}$. EPO906 and the liposomal EPO906 formulations were administered at different doses intravenously via the tail vein once weekly for four weeks. Intravenous injections of phosphate-buffered solution served as controls. Mice were euthanized after 28 days, if the tumor size exceeded $1000 \mathrm{~mm}^{3}$, or if loss of body weight reached $25 \%$. In addition to changes in body weight, toxicity was assessed by scoring diarrhea, which is the dose-limiting toxicity of EPO906 observed in clinical trials. For this purpose, the mice were placed singly in a cage on white filter paper for 30 minutes, and diarrhea was graded from 0 (no diarrhea) in steps of 0.5 up to a maximum of grade 3 (liquid stool).

\section{Statistical analysis}

The results are presented as the mean \pm standard error of the mean. The data were statistically analyzed using the KruskalWallis $\mathrm{H}$ test, with the post hoc Mann-Whitney $U$ test used to compare all groups. The differences in cumulative survival (Kaplan-Meier curves) were analyzed statistically using the log-rank test. $P$ values $<0.05$ were considered to be statistically significant.

\section{Results}

\section{Integrin $\alpha \mathrm{V} \beta 3$ expression and selective targeting using RGD-liposomes in vitro}

Semiquantitative reverse transcription PCR showed equal expression of integrin subunit $\alpha \mathrm{V}$ in the HUVEC, Kelly, and RH-30 cell lines (Figure 1A), whereas expression of integrin $\beta 3$ was much lower in Kelly cells compared with HUVEC and RH-30 cells. Stability of the particle size for EPO906-lip and EPO906-RGD-lip was investigated, and it was shown that the size for all preparations was stable over time (Supplementary Figure S1).

Flow cytometry analysis performed after four hours of incubation showed that RGD-lip were highly associated with HUVEC (Figure 1B) and RH-30 (Figure 1C) cells at $37^{\circ} \mathrm{C}$, whereas no cellular association was observed with Kelly cells (Figure 1D). Moreover, none of the three cell lines showed an association with PEG-lip or RAD-lip, or with RGD-lip at $4^{\circ} \mathrm{C}$, indicating high internalization of RGD-lip at $37^{\circ} \mathrm{C}$. Therefore, using Kelly and RH-30 cells for xenograft tumors, we could study the effects of RGD-lip interacting with integrin $\alpha \mathrm{V} \beta 3$ present on endothelial and rhabdomyosarcoma cells, but missing on neuroblastoma tumor cells.

\section{Inhibition of cell viability by EPO906 and liposomal EPO906 formulations}

EPO906 and its liposomal formulations inhibited viability in a dose-dependent manner in the HUVEC, Kelly, and RH-30 cell lines (Figure 2). No difference was observed between EPO906 and the liposomal formulations of any of the cell lines tested, but the efficacy of EPO906 and its liposomal formulations was more rapid and stronger in Kelly cells than in RH-30 cells, with inhibition of viability reaching $100 \%$ in Kelly cells after 48 hours at the highest dose tested (Figure 2B), whereas only 50\% inhibition was observed in RH-30 cells after 72 hours at the highest dose tested (Figure 2F). 
A

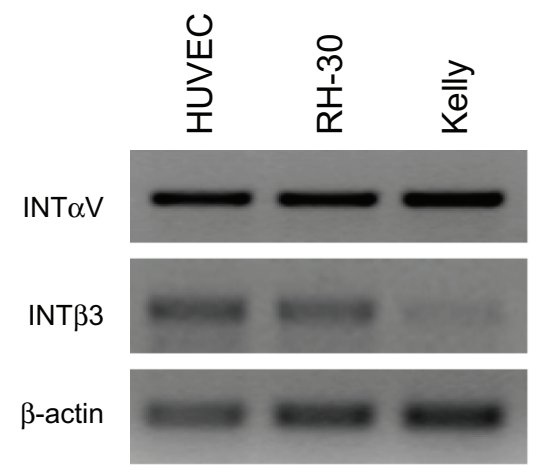

B

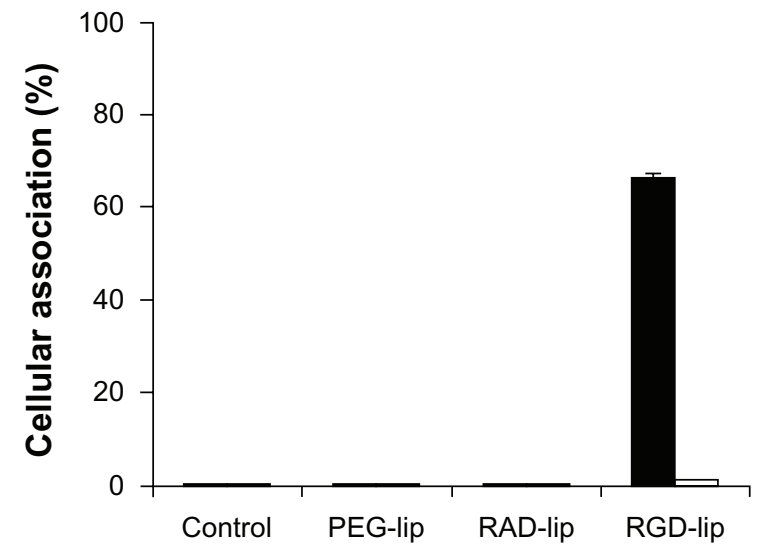

$37^{\circ} \mathrm{C}$

$4^{\circ} \mathrm{C}$

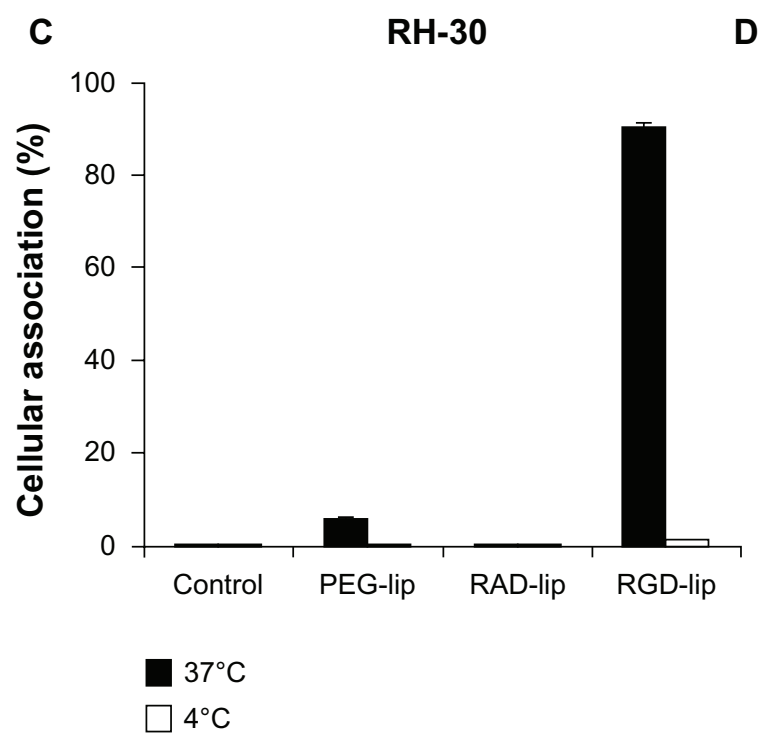

D

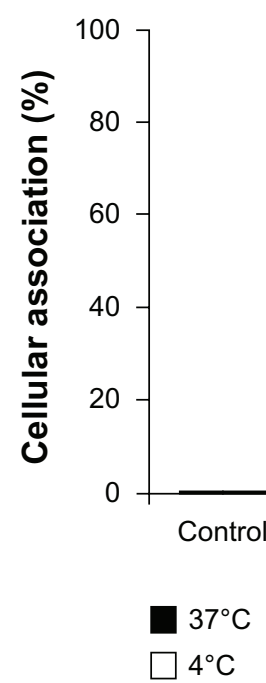

Figure I Integrin $\alpha \mathrm{V}$ and $\beta 3$ expression and integrin receptor targeting using RGD-liposomes in vitro. (A) Reverse transcription polymerase chain reaction for integrin $\alpha \mathrm{V}$ and $\beta 3$ fragments and the housekeeping gene $\beta$-actin in HUVEC, RH-30, and Kelly cells. (B-D) Association between RGD-liposomes and HUVEC (B), RH-30 (C), and Kelly cells (D).

Notes: HUVEC, RH-30, and Kelly cells were incubated with $300 \mathrm{nmol}$ rhodamine-PE-labeled placebo liposomes (PEG-lip, RGD-lip, or RAD-lip) for four hours at $4^{\circ} \mathrm{C}$ and $37^{\circ} \mathrm{C}$, and analyzed by flow cytometry. Data are presented as the percentage of fluorescent cells (mean \pm standard error of the mean).

Abbreviations: lip, liposomes; RGD, cyclo-(Arg-Gly-Asp-D-Phe-Cys) peptide; RAD, cyclo-(Arg-Ala-Asp-D-Phe-Cys) peptide; HUVEC, human umbilical vein endothelial cells; PEG, poly(ethylene glycol).

\section{Inhibition of tumor growth by EPO906 and its liposomal formulations in a mouse model of neuroblastoma}

Kelly xenograft tumors were grown in SCID mice until they reached $150-200 \mathrm{~mm}^{3}$. To define the most efficient and tolerated dose of EPO906 and liposomal EPO906 for further testing, we first treated mice with different doses of EPO906 and EPO906-lip (1.5 mg/kg, $2 \mathrm{mg} / \mathrm{kg}$, $2.5 \mathrm{mg} / \mathrm{kg}, 3 \mathrm{mg} / \mathrm{kg}$, Figure 3). No major differences in tumor growth were observed between the four doses used, indicating that $1.5 \mathrm{mg} / \mathrm{kg}$ was adequate to induce a potent antitumor effect. However, higher doses of EPO906 or EPO906-lip were associated with loss of body weight (Figure $3 \mathrm{C}$ and $\mathrm{D}$ ), and diarrhea and mortality were proportionally increased (Supplementary Table S1 and Figure S2).

We further investigated the effects of $1.5 \mathrm{mg} / \mathrm{kg}$ EPO906 and its liposomal formulations. Treatment with EPO906 and the liposomal formulations rapidly and significantly inhibited tumor growth after two days $(P<0.01$ versus 

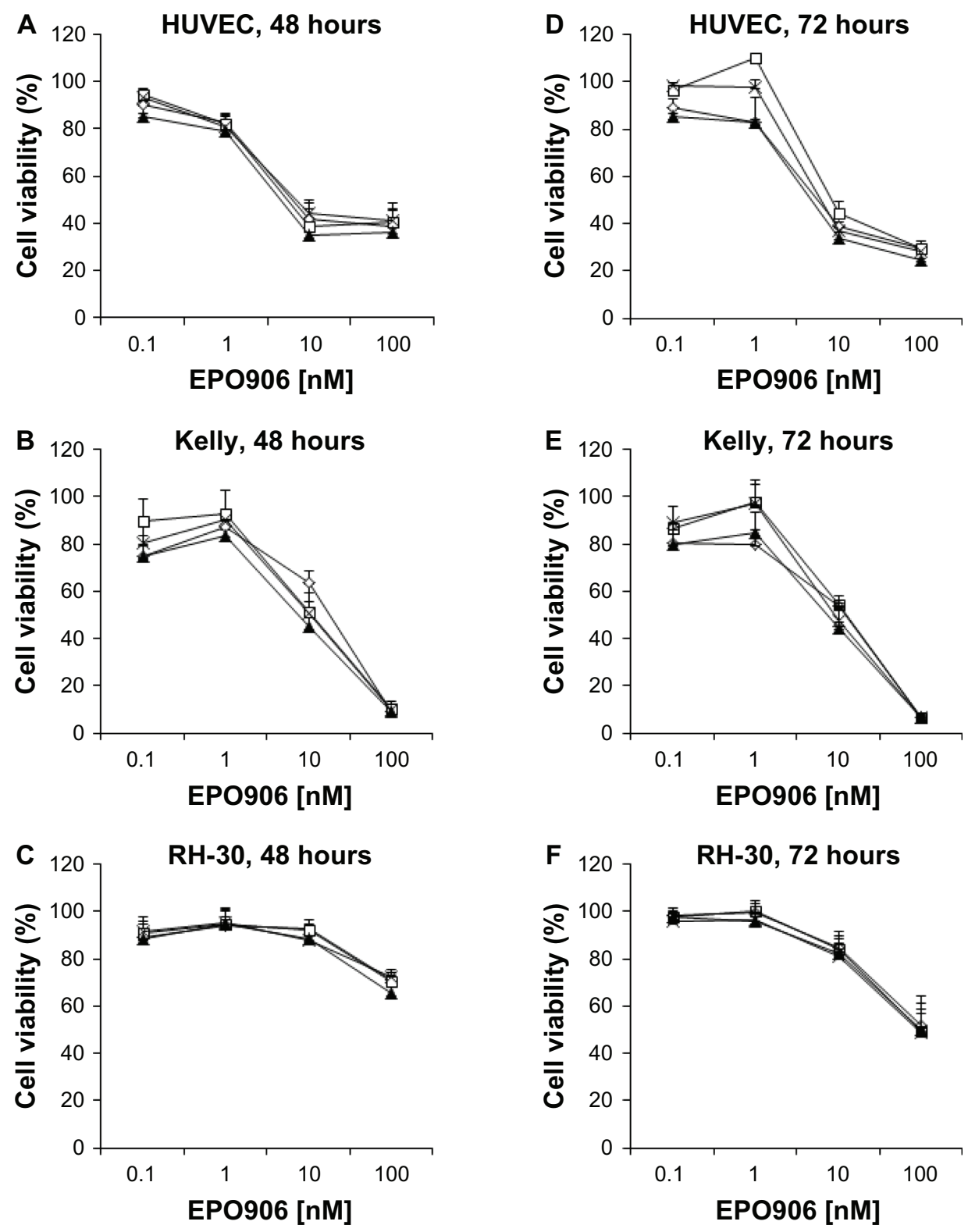

\begin{tabular}{|lc|}
\hline$\diamond$ EPO906 $(n=3-4)$ & \EPO906-RGD-lip $((n=3-4)$ \\
$\square$ EPO906-lip $(n=3-4)$ & $\times$ EPO906-RAD-lip $(n=3-4)$ \\
\hline
\end{tabular}

Figure 2 Inhibition of cell viability by EPO906 and EPO906 liposomal formulations in vitro. HUVEC (A and D), Kelly (B and E), and RH-30 (C and F) cells were incubated for four hours with EPO906 and EPO906 liposomal formulations (from 0.1 nM to $100 \mathrm{nM}$ ) and MTS assay was performed 48 hours or 72 hours later.

Note: Data are presented as the percentage of viable cells relative to untreated cells (mean \pm standard error of the mean).

Abbreviations: lip, liposomes; RGD, cyclo-(Arg-Gly-Asp-D-Phe-Cys) peptide; RAD, cyclo-(Arg-Ala-Asp-D-Phe-Cys) peptide; HUVEC, human umbilical vein endothelial cells; EPO906, epothilone B; PEG, poly(ethylene glycol).

controls, Figure 4A). Moreover, body weight decreased slightly over time (Figure 4B).

Cumulative survival was significantly increased in all the treatment groups compared with that in the control mice treated with phosphate-buffered solution, but no differences were observed between EPO906 and its liposomal formulations (Figure 4C).
Inhibition of tumor growth by EPO906 and liposomal EPO906 in a mouse model of rhabdomyosarcoma

RH-30 xenograft tumors were grown and treated as described above for the Kelly xenograft tumors.

Rapid tumor growth was seen in the control mice treated with phosphate-buffered solution (Figure 5A). In comparison, 

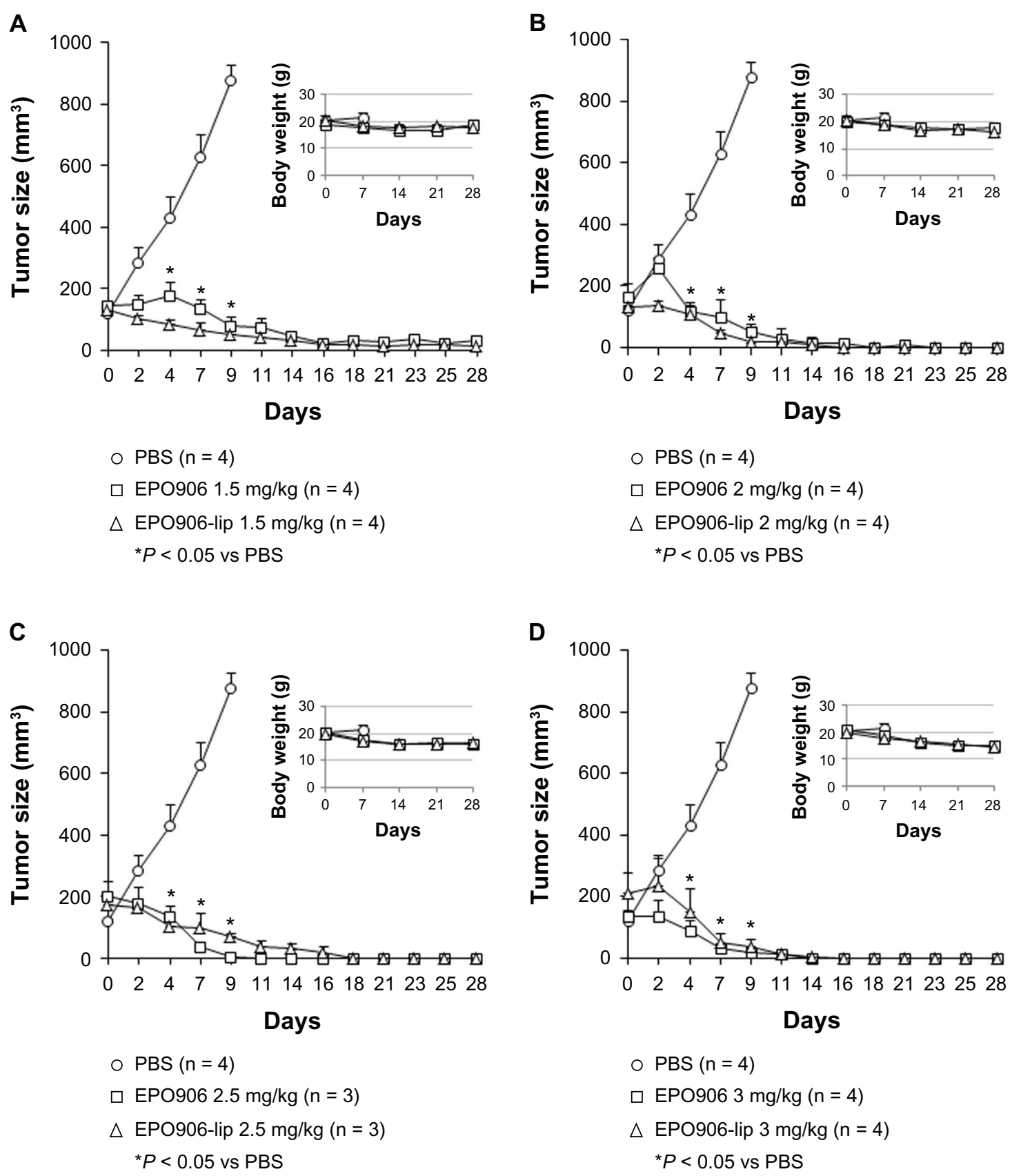

Figure 3 Treatment of Kelly neuroblastoma xenografts with increasing doses ( $1.5 \mathrm{mg} / \mathrm{kg}$ to $3 \mathrm{mg} / \mathrm{kg}$ ) of EPO906 and liposomal EPO906 formulations. A dose-finding study was performed to determine the optimal dose of EPO906 and EPO906-lip. Treatment with (A) $1.5 \mathrm{mg} / \mathrm{kg}$, (B) $2 \mathrm{mg} / \mathrm{kg},(\mathbf{C}) 2.5 \mathrm{mg} / \mathrm{kg},(\mathbf{D}) \mathrm{and} 3 \mathrm{mg} / \mathrm{kg}$.

Notes: Tumors were induced by subcutaneous injection of $20 \times 10^{6}$ Kelly cells into SCID bg/bg mice. Treatment with EPO 906 or EPO906-lip started when the tumor size reached $150-200 \mathrm{~mm}^{3}$, and was performed intravenously once a week for four weeks. Tumor size $\left(\mathrm{mm}^{3}\right)$ and body weight (g) are presented as the mean \pm standard error of the mean. $* P<0.05$ versus PBS.

Abbreviations: EPO906, epothilone B; lip, liposomes; PBS, phosphate-buffered solution.

EPO906 and its liposomal formulations induced a statistically significant decrease in tumor growth four days after the start of therapy ( $P<0.01$ versus controls, Figure 5A). This antitumor effect was more efficient when the animals were treated with EPO906-lip, and we had to stop evaluation of tumor size after 11 days of treatment with EPO906 and
EPO906-RGD-lip because the tumors had reached $1000 \mathrm{~mm}^{3}$ in size. Further, body weight decreased slightly over time (Figure 5B). Cumulative survival was significantly increased in all the treatment groups compared with the control mice, but no differences were observed between EPO906 and its liposomal formulations (Figure 5C). 

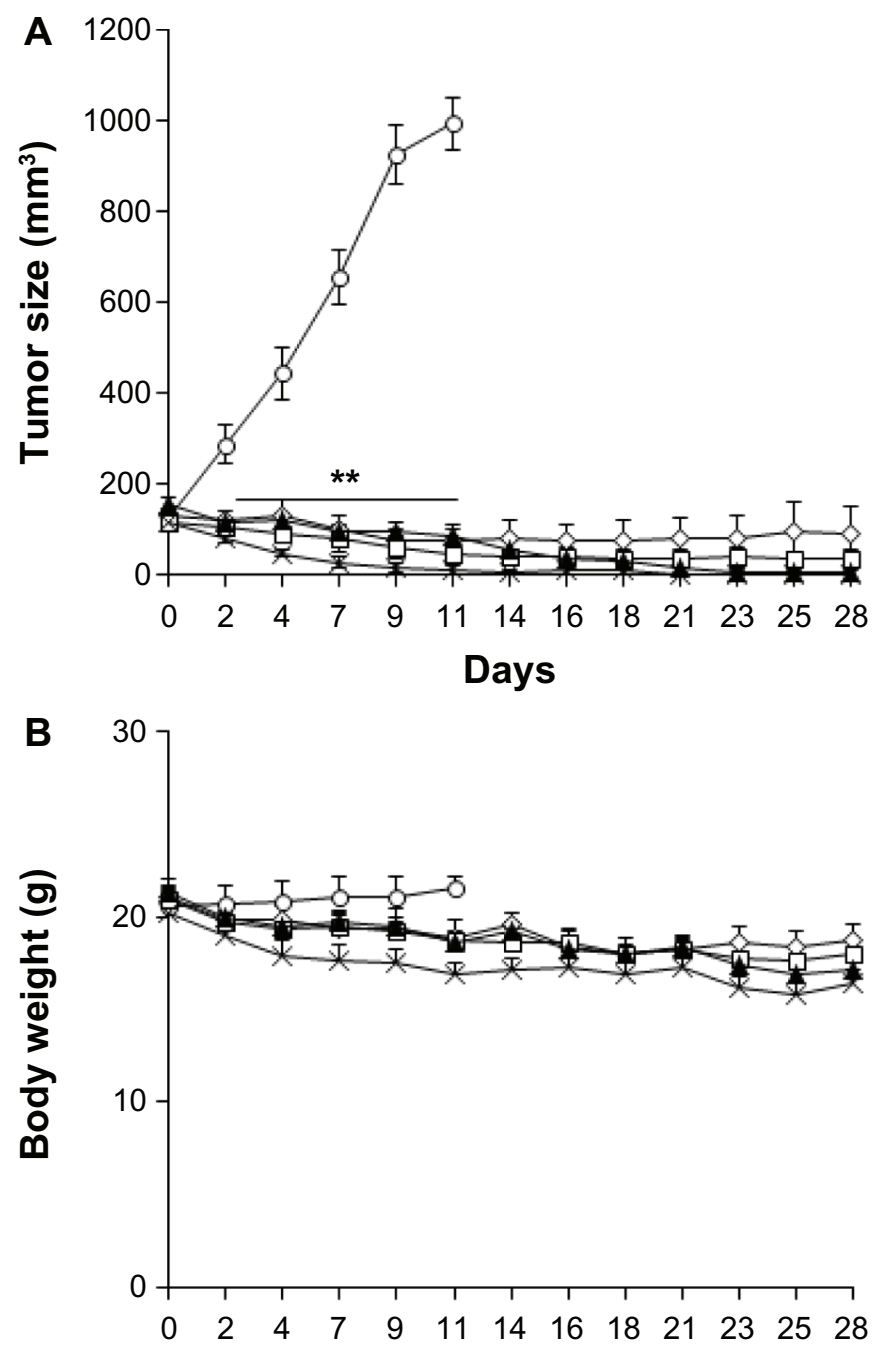

C

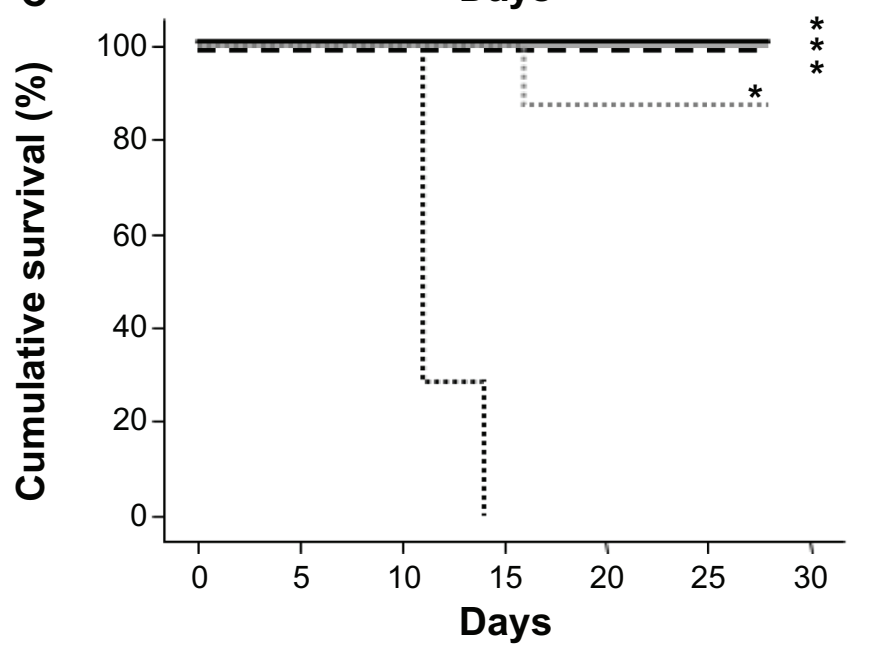

\section{$1.5 \mathrm{mg} / \mathrm{kg}$}

- PBS $(n=7)$

$\diamond \operatorname{EPO} 906(n=8)$

$\square$ EPO906-lip $(n=8)$

$\Delta$ EPO906-RGD-lip $(n=8)$

$\times$ EPO906-RAD-lip $(n=8)$

${ }^{*} P<0.01$ vs PBS

\section{$1.5 \mathrm{mg} / \mathrm{kg}$}

- PBS $(n=7)$

$\diamond$ EPO906 $(\mathrm{n}=8)$

口 EPO906-lip $(n=8)$

A EPO906-RGD-lip $(\mathrm{n}=8)$

$\times$ EPO906-RAD-lip $(n=8)$

\section{$1.5 \mathrm{mg} / \mathrm{kg}$}

$$
\begin{aligned}
\ldots \ldots . . . . & \text { PBS }(n=7) \\
--- & \text { EPO906 }(n=8) \\
- & \text { EPO906-lip }(n=8) \\
- & \text { EPO906-RGD-lip }(n=8) \\
\ldots . . . . . . \quad & \text { EPO906-RAD-lip }(n=8) \\
& { }^{*} P<0.05 \text { vs PBS }
\end{aligned}
$$

Figure 4 Treatment of Kelly neuroblastoma xenografts with $1.5 \mathrm{mg} / \mathrm{kg}$ EPO906 and liposomal EPO906 formulations. (A) Tumor size (mm³), (B) body weight (g), and (C) cumulative survival (\%).

Notes: Tumors were induced by subcutaneous injection of $20 \times 10^{6}$ Kelly cells into SCID bg/bg mice. Treatment with EPO906 or liposomal EPO906 formulations started when the tumor size reached $150-200 \mathrm{~mm}^{3}$, and was performed intravenously once a week for four weeks. The data are presented as the mean \pm standard error of the mean. $* P<0.05$ versus PBS; $* * P<0.01$ versus PBS.

Abbreviations: lip, liposomes; RGD, cyclo-(Arg-Gly-Asp-D-Phe-Cys) peptide; RAD, cyclo-(Arg-Ala-Asp-D-Phe-Cys) peptide; EPO906, epothilone B; PBS, phosphatebuffered solution. 


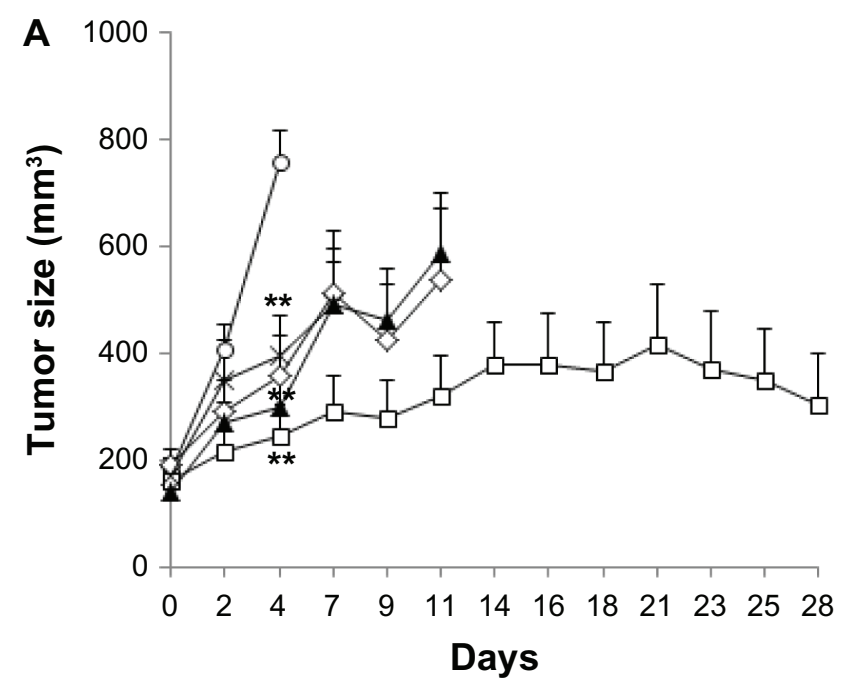

\section{$1.5 \mathrm{mg} / \mathrm{kg}$}

- $\operatorname{PBS}(n=9)$

$\diamond \operatorname{EPO906~}(n=9)$

$\square$ EPO906-lip $(n=9)$

\ EPO906-RGD-lip $(n=8)$

$\times$ EPO906-RAD-lip $(n=9)$

${ }^{* *} P<0.01$ vs PBS

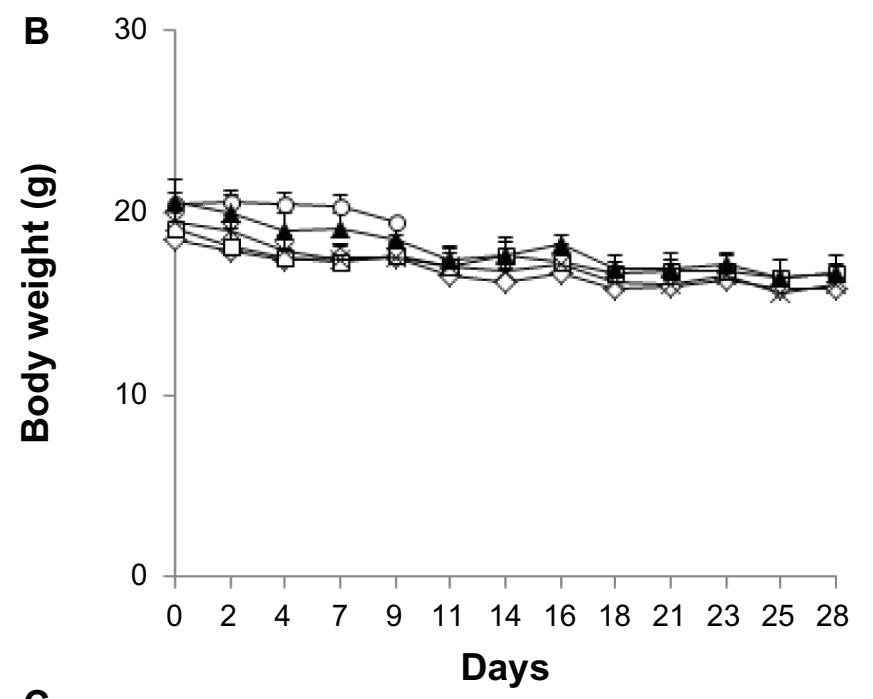

\section{$1.5 \mathrm{mg} / \mathrm{kg}$}

- $\operatorname{PBS}(n=9)$

$\triangle \operatorname{EPO906~}(n=9)$

$\square$ EPO906-lip $(n=9)$

\ EPO906-RGD-lip $(\mathrm{n}=8)$

$\times$ EPO906-RAD-lip $(n=9)$

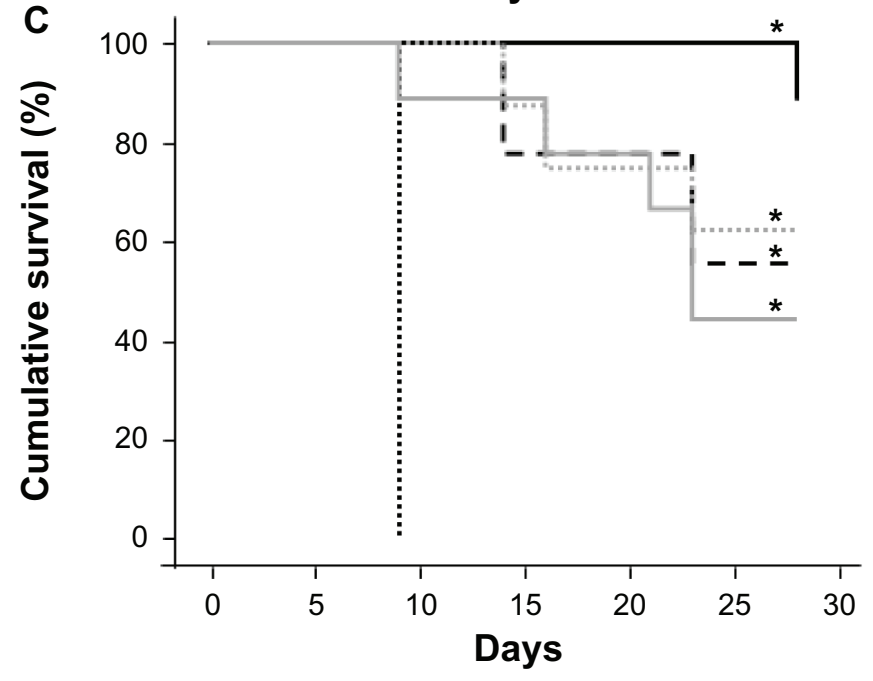

\section{$1.5 \mathrm{mg} / \mathrm{kg}$}

PBS $(n=9)$

- - - EPO906 ( $\mathrm{n}=9)$

EP0906-lip $(n=9)$

— EPO906-RGD-lip $(n=8)$

EP0906-RAD-lip $(n=9)$

${ }^{*} P<0.05$ vs PBS

Figure 5 Treatment of RH-30 rhabdomyosarcoma xenografts with $1.5 \mathrm{mg} / \mathrm{kg}$ EPO906 and liposomal EPO906 formulations. (A) Tumor size (mm³), (B) body weight (g), and (C) cumulative survival (\%).

Notes: Tumors were induced by subcutaneous injection of $20 \times 10^{6} \mathrm{RH}-30$ cells into SCID bg/bg mice. Treatment with EPO906 or liposomal EPO906 formulations was started when the tumor size reached $150-200 \mathrm{~mm}^{3}$, and was performed intravenously once a week for four weeks. The data are presented as the mean \pm standard error of the mean. $* P<0.05$ versus $P B S ; * P<0.01$ versus PBS.

Abbreviations: lip, liposomes; RGD, cyclo-(Arg-Gly-Asp-D-Phe-Cys) peptide; RAD, cyclo-(Arg-Ala-Asp-D-Phe-Cys) peptide; EPO906, epothilone B; PBS, phosphatebuffered solution. 


\section{Inhibition of tumor growth and enhancement of cumulative survival by low-dose EPO906 and its liposomal formulations in a mouse model of rhabdomyosarcoma}

The antitumor effect of $1.5 \mathrm{mg} / \mathrm{kg}$ EPO906 showed more potency when it was encapsulated in liposomes in the rhabdomyosarcoma model. Because EPO906 and its liposomal formulations were more toxic in the neuroblastoma model at higher doses, we oriented our study towards a lowdose therapy in rhabdomyosarcoma.

Low-dose $(0.5 \mathrm{mg} / \mathrm{kg}$ and $1 \mathrm{mg} / \mathrm{kg})$ EPO906 and its liposomal formulations were investigated. Treatment with $0.5 \mathrm{mg} / \mathrm{kg}$ showed no beneficial effects on tumor growth or survival (data not shown). With $1 \mathrm{mg} / \mathrm{kg}$, most of the mice in the treatment groups were euthanized before the end of the 28-day investigation period because they reached our defined criteria for stopping therapy (tumor size $>1000 \mathrm{~mm}^{3}$ ). However, EPO906-RGD-lip induced faster and more potent tumor growth inhibition compared with the other formulations, but this was not observed at the dose of $1.5 \mathrm{mg} / \mathrm{kg}$ (Figure 6A). Body weight decreased slightly over time (Figure 6B).

With regard to cumulative survival, use of low-dose EPO906 and its liposomal formulations resulted in death of most of the mice before the end of the treatment period, in accordance with our defined criteria for stopping therapy (Figure 6C), except in the EPO906-lip group where one of nine mice was still alive after 28 days $(P<0.05$ versus controls, Figure 6C) and in the EPO906-RGD-lip group where five of 10 mice were still alive after 28 days $(P<0.05$ versus controls, Figure 6C). Moreover, cumulative survival was significantly longer when mice were treated with EPO906-RGD-lip than when they were treated with EPO906 $(P<0.05$ versus EPO906, Figure 6C).

\section{Discussion}

Drugs that target microtubules are among the most commonly prescribed anticancer therapies. Vinca alkaloids, which depolymerize microtubules, are routinely administered in the treatment of pediatric solid tumors. ${ }^{28}$ The role of taxanes in pediatric oncology is not as clear. Paclitaxel and docetaxel have achieved a very moderate response in pediatric solid tumors and brain tumors at relapse, ${ }^{29,30}$ which is in contrast with their activity in adult carcinomas. Epothilones have emerged as a new class of microtubule-targeting drugs with the ability to overcome some of the problems associated with taxane-based therapy, and have shown potent antitumor activity. ${ }^{2,10}$ However, little is known about their effect in pediatric cancers. Ixabepilone, an epothilone B derivative, showed a broad spectrum of activity against a panel of pediatric tumor xenograft models. ${ }^{31}$ However; ixabepilone was inactive in a Phase II clinical trial in children and young adults with refractory solid tumors. ${ }^{32}$

Our study was designed to investigate the potential antitumor effect of EPO906 in two pediatric tumor models. In addition, a liposomal formulation of EPO906 was developed and characterized in vitro and in vivo. Given that EPO906 has antivascular and antiangiogenic properties ${ }^{7,10}$ in addition to cytotoxicity in tumor tissue, we assumed that it could be a good candidate for active targeting of tumor endothelium. For this purpose, we modified liposomes by adding cyclic RGD-peptides to their surface, forming integrin-targeting liposomes. Because neuroblastoma and rhabdomyosarcoma are both known to be highly vascularized, ${ }^{13,14}$ we predicted an additional benefit from this antiangiogenic therapeutic approach in addition to the antitumor effect.

Our results using a $1.5 \mathrm{mg} / \mathrm{kg}$ dose demonstrate for the first time the potent antitumor activity of EPO906 in vivo in its native or liposomal form in neuroblastoma and to a more moderate extent in rhabdomyosarcoma. This study also shows the feasibility of encapsulation of liposomal EPO906. This procedure did not enhance drug cytotoxicity assessed in vitro but did not negatively affect it neither, and no differences were observed between the different formulations. Moreover, the extent of its toxicity to tumor cells in vitro was correlated with the antitumor effect of EPO906 in vivo, with a very strong and rapid effect in neuroblastoma, leading to complete tumor regression, whereas a more moderate and heterogeneous response was observed in rhabdomyosarcoma. EPO906 was well tolerated, with no high-grade diarrhea or significant body weight loss observed. In addition, explanted organs (ie, liver, spleen) at the end of treatment did not show any macroscopic damage. It has been demonstrated that EPO906 is rapidly distributed from plasma to all tissues and eliminated slowly, with a longer retention in tumor and brain tissue. ${ }^{28}$ In the present study, pharmacokinetic profiling was not performed. It is important to point out that all our experiments were performed with EPO906 dissolved in PEG 300 as a control for the PEG-coated long-circulating liposomes encapsulating EPO906. We cannot exclude the possibility that this preparation prolongs the circulation time of EPO906 and increases its bioavailability in comparison 

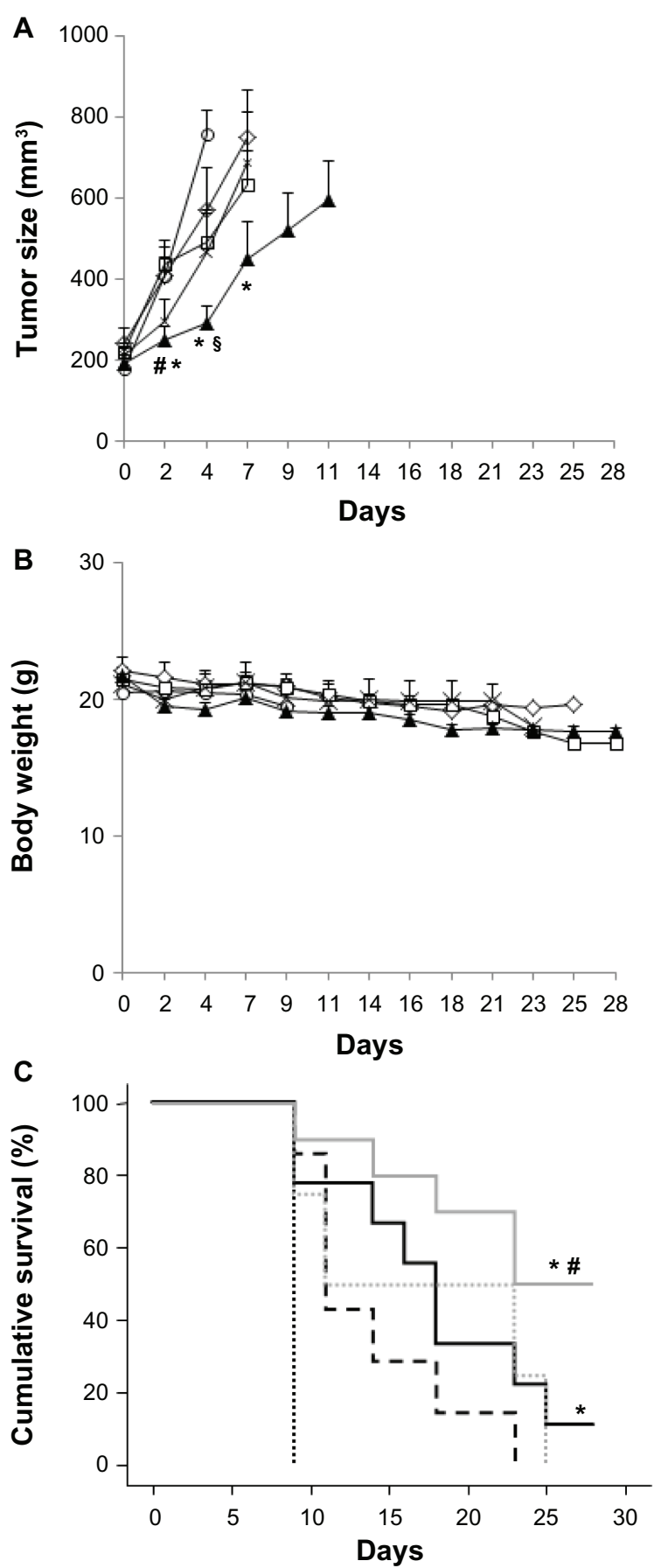

\section{$1 \mathrm{mg} / \mathrm{kg}$}

$\circ \operatorname{PBS}(n=9)$

$\diamond \operatorname{EPO906}(n=7)$

口 EPO906-lip $(n=9)$

\ EPO906-RGD-lip $(\mathrm{n}=10)$

$\times$ EP0906-RAD-lip $(n=4)$

${ }^{*} P<0.01$ vs PBS

$\$ P<0.05$ vs EPO906

${ }^{\#} P<0.05$ vs EPO906-lip

\author{
$1 \mathrm{mg} / \mathrm{kg}$ \\ ○ PBS $(n=9)$ \\ $\diamond \operatorname{EPO906}(n=7)$ \\ $\square$ EPO906-lip $(n=9)$ \\ \ EPO906-RGD-lip $(\mathrm{n}=10)$ \\ $\times$ EPO906-RAD-lip $(n=4)$
}

\section{$1 \mathrm{mg} / \mathrm{kg}$}

........ PBS $(n=9)$

- - - EPO906 $(n=7)$

EPO906-lip $(n=9)$

— EP0906-RGD-lip $(n=10)$

........ EPO906-RAD-lip $(n=4)$

${ }^{*} P<0.05$ vs PBS

${ }^{\#} P<0.05$ vs EPO906-lip

Figure 6 Treatment of RH-30 rhabdomyosarcoma xenografts with I mg/kg EPO906 and liposomal EPO906 formulations. (A) Tumor size (mm³), (B) body weight (g), and (C) cumulative survival (\%).

Notes: Tumors were induced by subcutaneous injection of $20 \times 10^{6} \mathrm{RH}-30$ cells into SCID bg/bg mice. Treatment with EPO906 or liposomal EPO906 formulations started when the tumor size reached $150-200 \mathrm{~mm}^{3}$, and was performed intravenously once a week for four weeks. The data are presented as the mean \pm standard error of the mean. ${ }^{*} P<0.05$ versus PBS; ${ }^{~} P<0.05$ versus EPO906; ${ }^{\#} P<0.05$ versus EPO906-lip.

Abbreviations: lip, liposomes; RGD, cyclo-(Arg-Gly-Asp-D-Phe-Cys) peptide; RAD, cyclo-(Arg-Ala-Asp-D-Phe-Cys) peptide; EPO906, epothilone B; PBS, phosphatebuffered solution.

with its nonpegylated form. This probably also explains the limitation of side effects compared with other studies. ${ }^{28}$

Tumors generally have leaky blood vessels and poor lymphatic drainage. While free drugs may diffuse nonspecifically, a carrier molecule can extravasate into tumor tissue via leaky vessels by the enhanced permeability and retention effect. ${ }^{19,20}$ Tissue distribution using ${ }^{111}$ In-labeled pegylated liposomes, RGD-liposomes, and RAD-liposomes showed that their localization in tumor tissue was the same. However, circulating levels of RGD-liposomes were 
lower than those of RAD-liposomes and pegylated liposomes, demonstrating their specific interaction with the tumor vasculature. ${ }^{17}$ Further, liposomes conjugated with RGD-peptides have been reported to target tumor endothelial cells without extravasation, ${ }^{25}$ and are located at the rim of the tumor, whereas RAD-liposomes are found throughout the whole tumor. ${ }^{33}$

In the neuroblastoma model, empty RGD-liposomes did not associate in vitro with Kelly cells, which have low expression of the integrin $\beta 3$ subunit, essential for binding of the RGD ligand with the specific $\alpha-\beta$ active site pocket, ${ }^{34}$ but we cannot exclude that RGD-liposomes bound to the tumor endothelium, as shown in vitro with HUVEC. However, their use to deliver EPO906 in neuroblastoma did not enhance the already strong antitumor effect of EPO906 or EPO906 encapsulated in PEG-liposomes. Moreover, the antitumor effects of EPO906-RAD-liposomes and EPO906-RGDliposomes were exactly the same in vivo, while the effect of RAD-liposomes was expected to be the same as PEGliposomes. Treatment of SCID mice with neuroblastoma using EPO906 dissolved in PEG 300 was already strong enough to inhibit tumor growth effectively, without triggering major side effects. In consequence, any effort to improve its delivery was not required. However, we did not treat the mice for longer than 28 days or monitor the animals after reducing and/or stopping the treatment.

Interestingly, in the mouse model of rhabdomyosarcoma, using RGD-liposomal EPO906 increased the antitumor effect as well as cumulative survival in the animals. Surprisingly, this beneficial effect was seen when we used a lower dose of EPO906 and its liposomal formulations. In general, cytotoxic agents are used at their maximum tolerated dose to induce rapid reduction of tumors, but this strategy often causes side effects and tumor resistance. Metronomic dosing, ie, continuous administration of lowdose chemotherapy over a protracted time course, targets the endothelial compartment of the tumor vasculature instead of having a direct cytotoxic effect on tumor cells. This ultimately deprives the tumor of its nutrient supply. ${ }^{35}$ A recent study using a human tumor-derived angiogenesis model confirmed a beneficial effect of EPO906 on tumor angiogenesis when used at very low doses for a prolonged period of time. ${ }^{36}$ In our study, use of low-dose EPO906-RGD-liposomes enhanced the antitumor effect and increased cumulative survival significantly compared with EPO906 and EPO906-lip. This result could be explained by the sensitivity of endothelial cells to low-dose chemotherapeutic drugs, ie, the metronomic chemotherapy dosing concept. Whether targeting liposomes improve uptake by cells in vivo is widely debated, but it seems that receptor-ligand interaction facilitates internalization and delivery of drugs into the cells. ${ }^{37,38}$ In our study, $1 \mathrm{mg} / \mathrm{kg}$ of RGD-liposomes showed greater endothelial cytotoxicity compared with PEG-liposomes, possibly because of a more appropriate ratio of integrins/RGD-ligands when a low dose was used, reducing the risk of receptor saturation and loss of receptor efficiency. Of note, the low dose of EPO906 $(1 \mathrm{mg} / \mathrm{kg})$ used in our study is $2.5-10$ times lower than that described so far in preclinical studies. ${ }^{28}$

Targeted drug delivery has been tested extensively in recent years. For example, targeted toxins are now available in brain tumor therapy and clinically approved nanoparticle-based cancer therapeutics, ${ }^{39}$ including liposomal formulations of anthracyclines, cytarabine, the nab formulation of paclitaxel, and the polymeric nanoparticle formulation of paclitaxel. ${ }^{40}$ However, in pediatric oncology, none of these has been studied in clinical trials nor approved by the regulatory authorities, although drug delivery exclusively to tumor cells is widely desired. Therefore, the RGD-liposomes described here could help to introduce these concepts, especially when treating young children and adolescents with cancer.

In conclusion, EPO906 showed a potent antitumor effect in vivo in two pediatric tumor models, ie, neuroblastoma and rhabdomyosarcoma. This effect was maintained when EPO906 was delivered to integrin-expressing cells using RGD-liposomes. Moreover, tumor targeting of EPO906 using RGD-liposomes enhanced its antitumor activity in rhabdomyosarcoma. Finally, the fact that low-dose EPO906RGD-liposomes had a potent antitumor effect, in addition to significantly increasing cumulative survival, opens up new opportunities for targeting liposomes as low-dose therapeutics in pediatric oncology.

\section{Acknowledgments}

We would like to acknowledge Peter Nöllke for the statistical analyses, Leah Bury for her support with the in vitro experiments, Celine Simonin for preparation and characterization of the liposome batches, and Paul MJ McSheehy for his strong support and recommendations concerning the design of the in vivo experiments. Jochen Rössler and Regine Süss received a grant from the Deutsche Forschungsgemeinschaft (RO 1263/9-1, PE 708/3-1).

\section{Disclosure}

The authors report no conflicts of interest in this work. 


\section{References}

1. Höfle G, Bedorf N, Steinmetz H, Schomburg D, Gerth K, Reichenbach H. Epothilone A and B - novel 16-membered macrolides and cytotoxic activity: isolation, crystal structure, and conformation in solution. Angew Chem Int Engl. 1996;35:1567-1569.

2. Bollag DM, McQueney PA, Zhu J, et al. Epothilones, a new class of microtubule-stabilizing agents with a Taxol-like mechanism of action. Cancer Res. 1995;55:2325-2333.

3. Altmann KH, Wartmann M, O'Reilly T. Epothilones and related structures - a new class of microtubule inhibitors with potent in vivo antitumor activity. Biochem Biophys Acta. 2000;1470:M79-M91.

4. Goodin S, Kane MP, Rubin EH. Epothilones: mechanism of action and biologic activity. J Clin Oncol. 2004;22:2015-2025.

5. Giannakakou P, Sackett DL, Kang YK. Paclitaxel resistant human ovarian cancer cells have mutant $\beta$-tubulins that exhibit impaired paclitaxeldriven polymerization. J Biol Chem. 1995;272:17118-17125.

6. Thorpe PE. Vascular targeting agents as cancer chemotherapeutics. Clin Cancer Res. 2004;10:415-427.

7. Bocci G, Nicolaou KC, Kerbel RS. Protracted low-dose effects on human endothelial cell proliferation and survival in vitro reveal a selective antiangiogenic window for various chemotherapeutic drugs. Cancer Res. 2002;62:6938-6943.

8. Oehler C, von Bueren AO, Furmanova P, et al. The microtubule stabilizer patupilone (epothilone B) is a potent radiosensitizer in medulloblastoma cells. NeuroOncol. 2011;13:1000-1010.

9. Woltering EA, Lewis JM, Maxwell PJ 4th, et al. Development of a novel in vitro human tissue-based angiogenesis assay to evaluate the effect of antiangiogenic drugs. Ann Surg. 2003;237:790-798.

10. Ferretti S, Allegrini PR, O’Reilly T, et al. Patupilone induced vascular disruption in orthotopic rodent tumor models detected by magnetic resonance imaging and interstitial fluid pressure. Clin Cancer Res. 2005;11:7773-7784.

11. Schrappe M, Reiter A, Zimmermann M, et al. Long-term results of four consecutive trials in childhood ALL performed by the ALL-BFM study group from 1981 to 1995 . Berlin-Frankfurt-Münster. Leukemia. 2000;14:2205-2222.

12. Möricke A, Zimmermann M, Reiter A, et al. Long-term results of five consecutive trials in childhood acute lymphoblastic leukemia performed by the ALL-BFM study group from 1981 to 2000. Leukemia. 2010;24: 265-284.

13. Zwann CM, Kearns P, Caron H, et al. The role of the 'innovative therapies for children with cancer' (ITCC) European consortium. Cancer Treat Rev. 2010;36:328-334.

14. Rengaswamy V, Kontny U, Rössler J. New approaches for pediatric rhabdomyosarcoma drug discovery: targeting combinatorial signaling. Expert Opin Drug Discov. 2011;6:1103-1125.

15. Rössler J, Taylor M, Geoerger B, et al. Angiogenesis as a target in neuroblastoma. Eur J Cancer. 2008;44:1645-1656.

16. André N, Verschuur A, Rossler J, Sterba J. Anti-angiogenic therapies for children with cancer. Curr Cancer Drug Targets. 2010;10:879-889.

17. Schiffelers RM, Koning GA, ten Hagen TLM, et al. Anti-tumor efficacy of tumor vasculature-targeted liposomal doxorubicin. J Control Release. 2003;91:115-122.

18. Plosker GL. Pegylated liposomal doxorubicin: a review of its use in the treatment of relapsed or refractory multiple myeloma. Drugs. 2008;68: 2535-2551.

19. Peer D, Karp JM, Hong S, Farokhzad OC, Margalit R, Langer R. Nanocarriers as an emerging platform for cancer therapy. Nat Nanotechnol. 2007;2:751-760.

20. Maeda H, Wu J, Sawa T, Matsumura Y, Hori K. Tumor vascular permeability and the EPR effect in macromolecular therapeutics: a review. J Control Release. 2000;65:271-284.
21. Dechantsreiter MA, Planker E, Mathä E, et al. N-methylated cyclic RGD peptides as highly active and selective alpha(V)beta(3) integrin antagonists. J Med Chem. 1999;42:3033-3040.

22. Kok RJ, Schraa AJ, Bos EJ, et al. Preparation and functional evaluation of RGD-modified proteins as alpha(V)beta(3) integrin directed therapeutics. Bioconjug Chem. 2002;13:128-135.

23. Dingemans AM, van den Boogaart V, Vosse BA, van Suylen RJ, Griffioen AW, Thijssen VL. Integrin expression profiling identifies integrin alpha5 and beta1 as prognostic factors in early stage non-small cell lung cancer. Mol Cancer. 2010;9:152-160.

24. Hynes RO. A reevaluation of integrins as regulators of experimental angiogenesis. Nat Med. 2002;8:918-921.

25. Mulder WJ, Castermans K, van Beijnum JR, et al. Molecular imaging of tumor angiogenesis using alphavbeta3-integrin targeted multimodal quantum dots. Angiogenesis. 2009;12:17-24.

26. Schönherr C, Touchene S, Wilser G, Peschka-Süss R, Francese G. Simple and precise detection of lipid compounds present within liposomal formulations using a charged aerosol detector. J Chromatogr. 2009;1216:781-786.

27. Schoenherr C, Haefele T, Paulus K, Francese G. Confocal Raman microscopy to probe content uniformity of a lipid based powder for inhalation: a quality by design approach. Eur J Pharm Sci. 2009;38: 47-54.

28. O'Reilly T, Wartmann M, Brueggen J, et al. Pharmacokinetic profile of the microtubule stabilizer patupilone in tumor-bearing rodents and comparison of anti-cancer activity with other MTS in vitro and in vivo. Cancer Chemother Pharmacol. 2008;62:1045-1054.

29. Hurwitz CA, Relling MV, Weitman SD, et al. Phase I trial of paclitaxel in children with refractory solid tumors: a Pediatric Oncology Group Study. J Clin Oncol. 1993;11:2324-2329.

30. Morris PG, Fornier MN. Microtubule active agents: beyond the taxane frontier. Clin Cancer Res. 2008;14:7167-7172.

31. Peterson JK, Tucker C, Favours E, et al. In vivo evaluation of ixabepilone (BMS247550), a novel epothilone B derivative, against pediatric cancer models. Clin Cancer Res. 2005;11:6950-6958.

32. Jacobs S, Fox E, Krailo M, et al. Phase II trial of ixabepilone administered daily for five days in children and young adults with refractory solid tumors: a report from the children's oncology group. Clin Cancer Res. 2010;16:750-754.

33. Mulder WJ, Strijkers GJ, Habets JW, et al. MR molecular imaging and fluorescence microscopy for identification of activated tumor endothelium using a bimodal lipidic nanoparticle. FASEB J. 2005;19: 2008-2010.

34. Humphries JD, Byron A, Humphries MJ. Integrin ligands at a glance. J Cell Sci. 2006;119:3901-3903.

35. Browder T, Butterfield CE, Kräling BM, et al. Antiangiogenic scheduling of chemotherapy improves efficacy against experimental drug-resistant cancer. Cancer Res. 2000;60:1878-1886.

36. Stalder MW, Anthony CT, Woltering EA. Metronomic dosing enhances the anti-angiogenic effect of epothilone B. J Surg Res. 2011;169: 247-256.

37. Federman N, Denny CT. Targeting liposomes toward novel pediatric anticancer therapeutics. Pediatr Res. 2010;67:514-519.

38. Xiong XB, Huang Y, Lu WL, et al. Intracellular delivery of doxorubicin with RGD-modified sterically stabilized liposomes for an improved antitumor efficacy: in vitro and in vivo. J Pharm Sci. 2005;94: 1782-1793.

39. Li YM, Hall WA. Targeted toxins in brain tumor therapy. Toxins. 2010;2:2645-2662.

40. Wang AZ, Langer RS, Farokhzad OC. Nanoparticle delivery of cancer drugs. Annu Rev Med. 2012;63:185-198. 


\section{Supplementary materials}

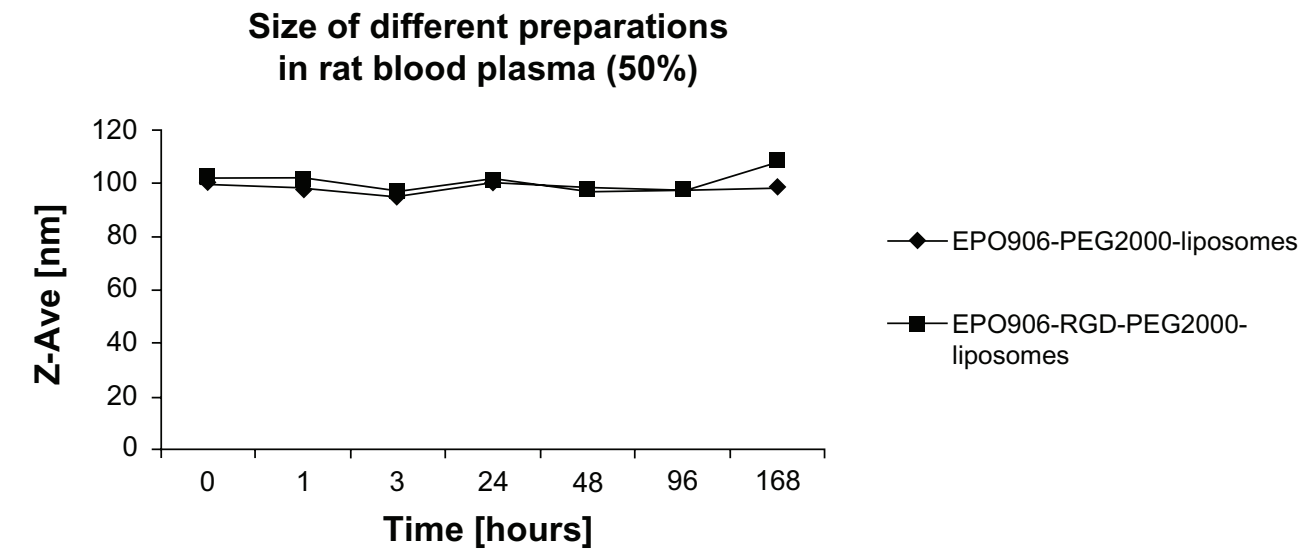

PI of different liposomal preparations in rat blood plasma $(50 \%)$

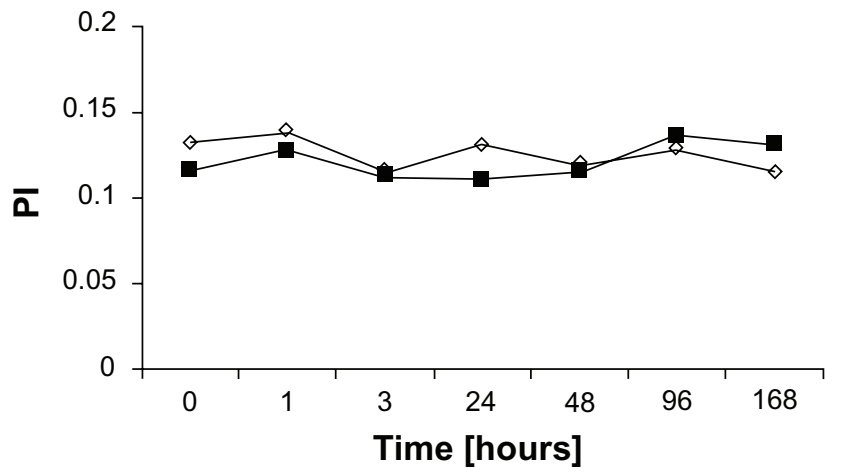

-EPO906-RGD-PEG2000-

liposomes

Figure SI Particle size and polydispersity index of EPO906-lip and EPO906-RGD-lip over time.

Notes: EPO906-lip and EPO906-RGD-lip preparations were mixed with rat plasma (I:I) and stored at $37^{\circ} \mathrm{C}$. Samples were taken at various time points to measure particle size and polydispersity index. In parallel, pure plasma was diluted in the same manner prior to measurement of size, and the plasma components showed an average diameter of $70 \mathrm{~nm}$, which was about half the size of the liposomal structures. Therefore, we consider that the plasma components did not interfere with measurements of particle size or polydispersity index.

Abbreviations: EPO906, epothilone B; lip, liposomes; PI, polydispersity index; PEG, poly(ethylene glycol); RGD, cyclo-(Arg-Gly-Asp-D-Phe-Cys) peptide; RAD, cyclo-(ArgAla-Asp-D-Phe-Cys) peptide.

Table SI Effect of increasing doses of EPO906 and EPO906lip on survival of mice with neuroblastoma (dose-finding study) showing numbers of dead animals/treated animals

\begin{tabular}{lll}
\hline Experimental group & Found dead & BW loss $>$ 25\% \\
\hline EPO906 I.5 mg/kg & $0 / 4$ & $0 / 4$ \\
EPO906-lip I.5 mg/kg & $0 / 4$ & $0 / 4$ \\
EPO906 $2 \mathrm{mg} / \mathrm{kg}$ & $0 / 3$ & $0 / 3$ \\
EPO906-lip $2 \mathrm{mg} / \mathrm{kg}$ & $0 / 3$ & $0 / 3$ \\
EPO906 $2.5 \mathrm{mg} / \mathrm{kg}$ & $1 / 3$ & $1 / 3$ \\
EPO906-lip $2.5 \mathrm{mg} / \mathrm{kg}$ & $0 / 3$ & $0 / 3$ \\
EPO906 $3 \mathrm{mg} / \mathrm{kg}$ & $2 / 4$ & $1 / 4$ \\
EPO906-lip $3 \mathrm{mg} / \mathrm{kg}$ & $\mathrm{I} / 4$ & $2 / 4$ \\
\hline
\end{tabular}

Abbreviations: EPO906, epothilone B; lip, liposomes; BW, body weight loss. 

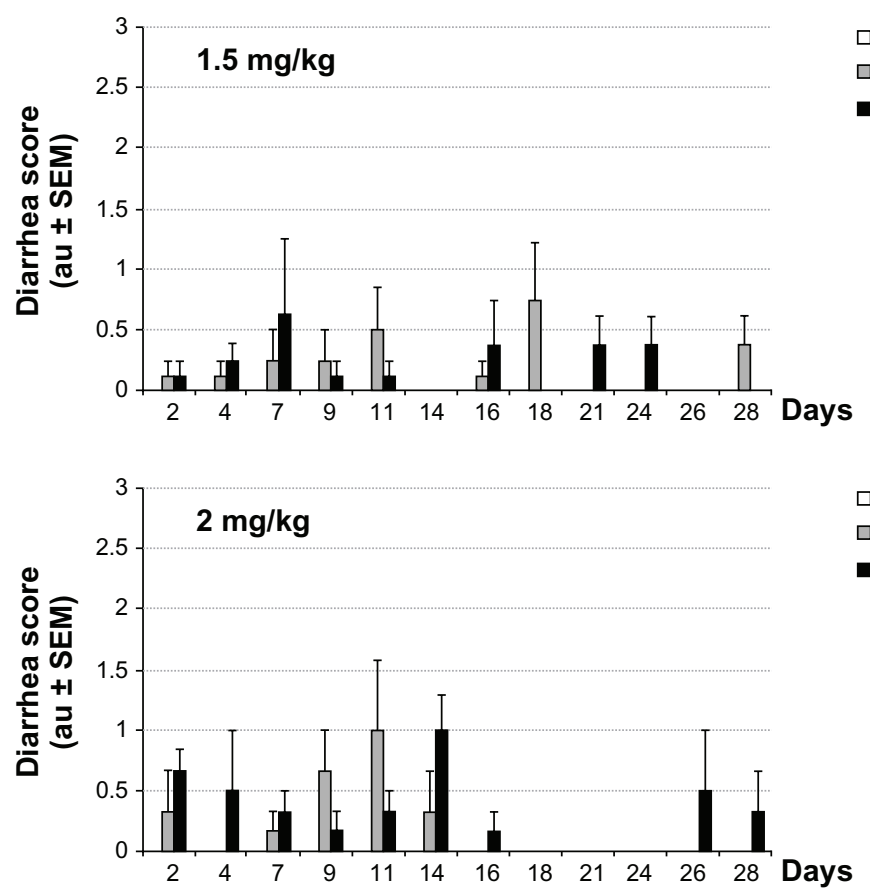

$\square$ PBS $(n=4)$

$\square$ EPO906 $(n=4)$

- EPO906-lip $(n=4)$

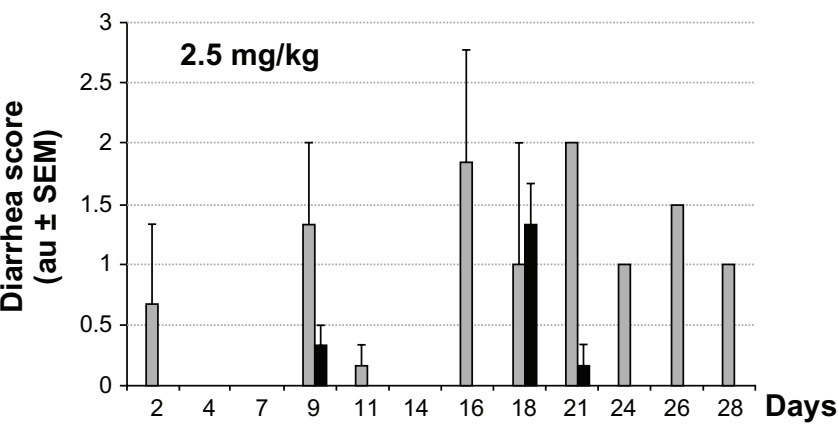

$\square$ PBS $(n=4)$

ㄷ EPO906 $(n=3)$

- EPO906-lip $(n=3)$

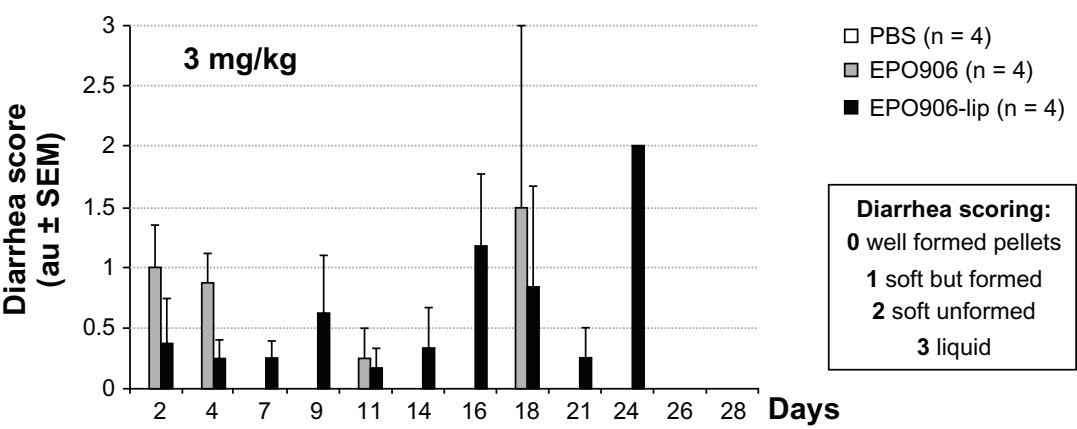

Figure S2 Effect of increasing doses of EPO906 and EPO906-lip on stool consistency in neuroblastoma (diarrhea score).

Notes: Tumor-bearing mice were singly placed in a cage on white filter paper for 30 minutes and diarrhea was graded from 0 (no diarrhea) in increments of 0.5 up to a maximum of grade 3 (liquid stool). Diarrhea was scored every 2-3 days. The results are presented as mean arbitrary units \pm standard error of the mean.

Abbreviations: au, arbitary unit; EPO906, epothilone B; lip, liposomes; PBS, poly(ethylene glycol); SEM, standard error of the mean.

International Journal of Nanomedicine

Dovepress

\section{Publish your work in this journal}

The International Journal of Nanomedicine is an international, peerreviewed journal focusing on the application of nanotechnology in diagnostics, therapeutics, and drug delivery systems throughout the biomedical field. This journal is indexed on PubMed Central, MedLine, CAS, SciSearch ${ }^{\circledR}$, Current Contents ${ }^{\circledR} /$ Clinical Medicine, $\square \operatorname{PBS}(n=4)$

$\square \operatorname{EPO} 006(n=3)$

- EPO906-lip $(n=3)$ 